\title{
Pensar la ciudad en otras escalas: Un balance teórico para el fenómeno urbano en el Perú a partir de "Jauja Monumental"
}

\section{Omar Correa}

Bachiller en Antropología por la PUCP. Miembro del Grupo de Investigación de Antropología y la Ciudad (GIAC) - PUCP. e-mail: omar.correa@pucp.pe

\section{Resumen}

¿Cómo pensar la ciudad en el Perú fuera de Lima? El presente artículo explora dos acercamientos teóricos para ser tomados en cuenta en el estudio de ciudades intermedias, a partir del caso del "Jauja Monumental", proyecto de revalorización urbana desarrollado en dicha ciudad de la sierra central.

A partir de este caso, se exploran y discuten dos acercamientos teóricos que permiten aprehender y analizar el caso en su complejidad. Estos son la propuesta de la "producción del espacio" (PdE), desde la tradición marxista de Lefebvre, y la propuesta latinoamericana de los "imaginarios urbanos" (IU) desde Hiernaux, Silva y Lindón. De esta manera, se busca alimentar al debate teórico sobre las ciudades en el Perú, desde una propuesta que atienda a las variables económico-políticas, pero también culturales y simbólicas por las que ciudades de otras escalas y locaciones más allá de la metrópoli limeña se van (re)configurando en el tiempo.

\section{Palabras clave}

Antropología y ciudad intermedia, producción del espacio, imaginarios urbanos. 


\section{Thinking over the city at different scales: A theoretical balance for the Peruvian urban question from "Jauja Monumental"}

\section{Omar Correa}

Bachelor in Anthropology from the PUCP. Member of the Anthropology and City

Research Group (GIAC) - PUCP. e-mail: omar.correa@pucp.pe

\section{Abstract}

How to ponder 'the city' in Peru outside of Lima? This article discusses two theoretical approaches to be taken into account in the study of intermediate cities, from the case of "Jauja Monumental": urban project which consisted in a revalorization of the architectural heritage existing at the monumental zone of this Andean city.

From this case, I explore and discuss two theoretical approaches, which allow to apprehend and analyze the case with sufficient deepness and flexibility. These are, in the first place, the proposal of the "production of space" (PdE), coming from Lefebvre and the Marxist tradition. As, in the second place, the Latin American proposal of the "imaginarios urbanos" (IU) from authors such Hiernaux, Silva and Lindón. In this way, the current article aims to feed the theoretical debate on cities in Peru, from a proposal that addresses the economic-political, but also cultural and symbolic factors through which cities beyond metropolitan Lima are (re) configured over time.

\section{Keywords}

Urban anthropology, Anthropology and the intermediate city, production of space, urban imaginaries 


\section{Introducción}

Cuando hablamos de los fenómenos urbanos en Perú, el anclaje significativo en la ciudad de Lima viene asociado casi por antonomasia. Y, ciertamente, existen razones para que esto suceda. Desde la década de 1940, la capital del Perú, que no es un caso excepcional en el proceso de urbanización "macrocefálico" de diversos países latinoamericanos, ha recibido -por diversas razones ampliamente investigadas- un flujo masivo de personas desde otras regiones del territorio nacional. Esta situación, junto con los cambios en la producción del espacio físico y dinámica social cotidiana que se desprenden de esta, ha generado una serie de estudios desde diversas disciplinas -tales como las ciencias sociales, la geografía, la arquitectura y urbanismo, entre otras- los cuales han intentado (algunos con más éxito que otros) comprender sus múltiples aspectos constituyentes.

No obstante, los procesos migratorios en el país no solo se han dado hacia la ciudad capital. De hecho, esta situación ha venido siendo más patente en los últimos años, como se menciona para un informe de la Organización Internacional para las Migraciones (Sánchez Aguilar, 2015). Ahí se puede ver que la migración interna ahora tiene como destinos a otras ciudades "menores" (capitales regionales, especialmente de la costa). El crecimiento de estas ciudades, como se propone en tal estudio, se da principalmente como resultado de procesos de conectividad con circuitos mayores de intercambio de bienes y fuerza de trabajo (ya sea el comercio o las actividades extractivas).

Esta coyuntura de urbanización creciente y migración interna llama la vista de la producción académica peruana a una situación aparentemente intuitiva: que existen ciudades y dinámicas urbanas también fuera de Lima. Tal situación, por más obvia que parezca, le es una especial novedad a especialidades como la antropología, que fuera de algunas ciudades muy presentes en el imaginario del país, tiene una producción académica ${ }^{1}$ que-desde mi posición- parece reproducir una espacialización marcadamente dicotómica entre Lima (urbana) y el resto del Perú (rural); producto de la asunción de una correspondencia muy simplista entre "lo urbano" y la escala metropolitana ${ }^{2}$. Así mismo, cuando esto (el prestar atención a dinámicas urbanas fuera de Lima) se ha logrado, muy pocas veces se ha prestado suficiente atención a las relaciones que se tejen entre los grupos habitantes y el espacio y la arquitectura, aspectos fundamentales mediante los cuales se vive y expresa la vida social en las ciudades.

Con este demandante panorama, entonces, ¿cómo comenzar a pensar la ciudad más allá de lo metropolitano? ¿Y qué herramientas teóricas pueden ser útiles para lograrlo? Lejos de pretender "descubrir la pólvora" o asumir -pretenciosamenteesta investigación como pionera en algún campo académico, el caso presentado en este artículo busca ser un corto aporte que busca ampliar la mirada hacia 'nuevos' espacios urbanos en el Perú, como lo son las ciudades intermedias.

1 Cuando menciono la "producción académica" me refiero a la producción hegemónica desde la academia antropológica limeña, que es la que cuenta con mayor difusión y alcance. Hago esta aclaración, ya que imagino que en tesis de universidades de otras provincias sí se puede encontrar una atención mayor a estos procesos, por su mayor cercanía -en términos geográficos y simbólicos- a estos.

2 Para una revisión bibliográfica detallada, ver el artículo de Vega Centeno y Cockburn en el texto de Metzger et. al. (2016) 
Esto, específicamente, reseñando una discusión teórica que permita asir con suficiente profundidad y flexibilidad uno de sus fenómenos.

Para tal objetivo, este texto está organizado en tres momentos. En el primero, reseño brevemente el caso de "Jauja Monumental" con una descripción que presenta este evento y los actores que en él han intervenido. En el segundo, parte central de este artículo, realizo un balance crítico a partir de la presentación y discusión de dos propuestas teóricas que ayudarían a aprehender este caso. Esto motiva, en un tercer momento, a esbozar algunas reflexiones finales.

\section{Un vistazo rápido ${ }^{3}$ a "Jauja Monumental"}

Jauja es una ciudad andina con una historia colonial y republicana de larga data. Esto se manifiesta en su arquitectura, en las maneras en las cuales es representada hacia el exterior desde la literatura ${ }^{4}$, y en los recuerdos -siempre negociados- de su población. Esta ciudad es la capital de una de las nueve provincias de la región Junín. Así, Jauja destaca por su ubicación en el valle del Mantaro: valle que a lo largo de la historia se ha caracterizado por su gran articulación con las dinámicas socioeconómicas regionales y nacionales. Principalmente, esta se ha dado a partir de la agricultura (es uno de los valles más productivos del Perú), la minería (por su cercanía con centros mineros y metalúrgicos, como La Oroya y Cerro de Pasco) y -como consecuencia de las dos anteriores, además de su accesibilidad y centralidad geográfica en el país- del comercio.

En el año 2008, desde la Dirección Regional de Comercio exterior y Turismo (DIRCETUR)- Junín, (que es una institución estatal de escala regional adherida a los gobiernos regionales) se planteó y ejecutó el proyecto llamado "Puesta en valor, recuperación y conservación de la zona monumental de la ciudad de Jauja, primera capital histórica del Perú -Región Junín”, más conocido y promovido con el nombre de "Jauja monumental".

Tal proyecto consistió en la reparación y arreglos de algunas casonas representativas, de la plaza principal, y de las dos iglesias principales de la zona monumental de la ciudad, así como la peatonalización del jirón principal. A la par, consistió en la presentación de un libro y la puesta en marcha de una estrategia para promover el turismo en la ciudad y en la región.

"Jauja monumental" tuvo como antecedente la demarcación de una zona monumental en la región norcentral de la ciudad, la cual se llevó a cabo por el Municipio provincial de Jauja con la dirección regional del entonces Instituto Nacional de Cultura (hoy Ministerio de cultura), algunos años atrás. Este proyecto tuvo una duración aproximada de dos años y atravesó un desarrollo bastante accidentado desde sus comienzos, especialmente por la manera en que fue ejecutado y por los cambios políticos que se dieron en paralelo a la ejecución del proyecto, y que tuvieron consecuencias notables en su desarrollo.

3 Por motivos de espacio y de los objetivos del artículo, esta descripción del caso sirve exclusivamente para contextualizarlo. Para una descripción más detallada de su desarrollo, los actores y los discursos que se generaron en torno a "Jauja Monumental", ver Correa Solís (2018).

4 Para acercarse a este tópico, las reseñas más logradas son las de Rivera Martínez (1999) y (2012). 
En el transcurso del proyecto intervinieron, en distintos grados y escalas, múltiples actores, tanto estatales como extraestatales. En un primer avistamiento, podrían ser reconocidos las agencias estatales (DIRCETUR, INC, gobierno regional Junín, Municipalidad de Jauja), las asociaciones civiles que se conformaron para servir de nexo entre las agencias ejecutoras y la población (como el Patronato, y el Frente de Defensa de Jauja), las asociaciones culturales (que jugaron un papel más de promoción del proyecto en distintos espacios), la prensa (conductores radiales locales), los comerciantes y residentes de las zonas intervenidas, y los transportistas (con sus asociaciones).

Todos estos actores mencionados cuentan con distintos imaginarios y "proyectos de ciudad" -en términos estéticos y políticos-, además de una producción y apropiación concreta y cotidiana de su espacio, que tiene que ver, entre otras cosas, con el lugar que ocupa Jauja en dinámicas económicas mayores: 1) como capital de provincia, que implica la presencia de instituciones estatales y una dinámica mayor de comercio interno con los otros distritos, y 2) por su ubicación en un valle tan productivo y agrario como el valle del Mantaro.

En ese sentido, "Jauja monumental" fue un evento que explicitó las tensiones y luchas simbólicas dentro de la dinámica social jaujina en lo que respecta a los distintos planteamientos sobre la ciudad de Jauja en términos estéticos ("lo bello" en relación con la arquitectura), y político-económicos ("el desarrollo" para la ciudad y la provincia), así como a las relaciones de poder que trascienden los espacios en los cuales estos proyectos de ciudad son enunciados. Este proyecto condensa y visibiliza mucha de esta mencionada dinámica de negociación identitaria de la ciudad, esta vez en relación con su espacio.

\section{¿Cómo acercarnos a "Jauja Monumental”?: Un balance teórico}

El caso de "Jauja Monumental" nos plantea una situación compleja en el que intervienen, sobre un mismo espacio, específicamente sobre una zona monumental, distintos actores, con sus propias y cotidianas prácticas y simbolizaciones sobre la ciudad. Por tal razón, surge la necesidad de encontrar un marco teórico que nos permita aprehender con justicia sus múltiples aspectos constituyentes.

Desde la reflexión planteada en los artículos del texto de Canziani y Shejtman (2013), entendemos que las ciudades intermedias son conglomerados físicos y sociales que deben ser entendidos, más allá de su dimensión demográfica (también importante), principalmente desde su dimensión económica, en tanto se generan como espacios "intermediarios" entre dinámicas de producción rural y espacios más metropolitanos. Sin embargo, como bien mencionan Salcedo y Zeiderman (2008), la ciudad no es solo realidad física y social, sino que además, es una realidad discursiva, y por tanto existente también en el plano de los códigos culturales. Silva (2006), subrayando un argumento cercano, menciona que el estudio de "la ciudad" desde la antropología debe también atender a los procesos simbólicos mediante los cuales las personas y grupos dotan de significado a ciertos espacios, y a partir de los cuales accionan nuevas prácticas de re-creación de la ciudad. 
El recordar tales exigencias al momento de reflexionar sobre una ciudad con las características de Jauja, nos llevan a la exploración de dos conjuntos conceptuales que provienen de distintas tradiciones teóricas, y que privilegian aspectos diferentes en su análisis de los fenómenos urbanos. Estos son los marcos de la "Producción del espacio" y de los "Imaginarios urbanos".

La Producción del Espacio (desde ahora PdE) es un concepto proveniente de la geografía social marxista. Fue propuesto originalmente por Henri Lefebvre como una manera nueva de comprender analíticamente el espacio en su aspecto social, usualmente obviado en la producción académica occidental. En "La Producción del Espacio" (2013), Lefebvre sintetiza sus nociones de espacio en una teoría sistematizada que lo entiende como un elemento anclado en la vida social, y por lo tanto producto social, al mismo que generador de determinadas prácticas, y en este sentido, productor social.

El autor parte de una crítica a las entradas tradicionales al concepto de espacio que generalmente se han realizado desde la filosofía de Kant, Descartes y Hegel; los conceptos matemáticos y físicos del espacio-tiempo, así como también desde el urbanismo y la semiótica. Lefebvre señala que tales acercamientos al concepto de espacio tienen dos falencias: la primera, de no tener ninguna interconexión entre ellas, lo cual las convierte en simples "ideologías" sobre el espacio (Baringo Ezquerra, 2014; Shields, 1988, pp. 7-17); y la segunda es que además ignoran el aspecto social que construye el espacio, en tanto lo conciben como un contenedor inerte e inmanente -espacio mental-, así como ignoran las contradicciones entre la práctica, la percepción y la concepción del espacio (Martínez 2013: 47), por lo cual impiden la comprensión de la verdadera operación del espacio en la conducta diaria del poder estatal y capitalista (Shields, 1988) y son, en última instancia, discursos descriptivos sobre el espacio, pero que no aportan a un conocimiento del espacio (Lefebvre, 2013, p. 68).

Frente a estos acercamientos tradicionales, Lefebvre propone una "teoría unitaria del espacio" que lo codifique como categoría analítica (Baringo Ezquera, 2014). En este planteamiento, se busca tomar en cuenta sus aspectos físicos (relacionado a la experiencia sensorial), mentales (el de los filósofos y matemáticos) y sociales (producto y productor de relaciones sociales), los cuales se implican y sostienen mutuamente (Lefebvre 2013, pp. 75).

El autor francés elucida a lo largo de su texto la comprensión de un aspecto no visto en el enfoque tradicional: el carácter social del espacio. Parte de la premisa de que "el espacio (social) es un producto (social) [...] y sirve tanto de instrumento del pensamiento como de la acción; que al mismo tiempo constituye un medio de producción, un medio de control, de dominación y de poder, pero que escapa parcialmente a los que se sirven de él" (2013, pp. 86), para lograr comprender al espacio como un ente producto de relaciones económicas y simbólicas en su momento histórico. 
En el proceso de articulación constante de esos tres niveles, se genera una representación simbólica de las relaciones de producción que engloba las relaciones de poder dentro de una sociedad. Tanto las representaciones hegemónicas del espacio, que contienen las representaciones en los edificios, los monumentos, etc. como las representaciones "clandestinas" o subterráneas, que construyen desde la práctica los usuarios del espacio, y que podrían ser expresadas potencialmente en el arte (Lefebvre 2013: 92).

De esta manera, en su teoría va tomando forma la tríada conceptual que representa diferentes momentos del espacio:

1. La práctica espacial, o el espacio percibido, a partir de la sensorialidad, son las apropiaciones, transformaciones y producción concreta del espacio, dentro de un modo de producción específico.

2. Las representaciones del espacio, o el espacio concebido, son los discursos acerca del espacio que acompañan estas prácticas, y se expresan en un campo simbólico, como los mapas, los proyectos urbanísticos, etc.

3. Los espacios de representación, o el espacio vivido a través de imágenes y símbolos que lo acompañan, es el espacio de los habitantes/usuarios y muchas veces juega el papel de una "espacialidad de resistencia" (Oslender, 2002) a partir del cual se contesta a las representaciones del espacio y se proponen modos alternativos de producción, o "espacios diferenciales". Dichos momentos del espacio mantienen una relación constantemente dialéctica, en la cual el capital se continúa expandiendo en su continuo proceso de "destrucción creativa" (2013, pp. 92-98; Shields 1988; Harvey 1989, 1999 en Castillo 2015).

La teoría de Lefebvre es muy potente para entender el espacio en términos de las relaciones de poder económico, político y simbólico que se tienden en las sociedades, ya que como concepto anclado en la tradición marxista, y por estar en diálogo con perspectivas como la economía política, comprende al espacio "local" en su relación necesaria con las dinámicas económicas y políticas en la cual se articula la zona estudiada, a la vez que identifica las relaciones en su interior entre los actores múltiples que intervienen en este proceso.

Como reseña Castillo (2015), además, la PdE discute y critica la distinción que hace la geografía humanística, desde autores como Agnew (1987), Tuan (1979) o el mismo Creswell (2008), de las categorías "espacio" de "lugar", a partir de la ausencia o presencia (respectivamente) de una apropiación simbólica. Al entender al espacio como un ente también social y producto de relaciones materiales y simbólicas, la teoría de la PdE propone la apropiación simbólica como un aspecto inherente a la misma categoría de "espacio". Sin embargo, esta posición teórica encuentra sus límites al intentar ser aplicado en este caso específico. 
En primer lugar, a pesar de que Lefebvre realiza una teoría de un nivel de abstracción que discute con 'universales', lo que escribe lo hace en un contexto específico. El autor realiza su obra en un momento en el que los sistemas económicos tenían una lógica predominantemente estatal, y es el Estado capitalista quien impone su lógica avasalladora (2013:83-84). En el caso jaujino la situación es distinta: luego de los ajustes estructurales en los años noventa, la apertura del libre mercado y las transformaciones políticas que acompañan las reformas económicas, en las que se propone un nivel cada vez menor de intervención estatal, el Estado no es más 'el único' actor que interviene y produce simbólica o materialmente el espacio. Por el contrario, existe una red cada vez más compleja de actores estatales y privados, quienes cuentan con capacidad activa de imaginar y transformar su espacio; no obstante, desde posiciones muy desiguales de poder en torno al capital necesario para transformar efectivamente, y en torno a la legitimidad con la que cuenta su accionar sobre el espacio de una zona monumental.

Sobre este punto, debemos mencionar que la tríada que propone el autor parece por momentos problemática, al suponer a priori actores activos y pasivos en los momentos de producción simbólica del espacio. Castillo (2015) critica esta división dicotómica entre productores y usuarios del espacio, por lo que retoma la visión de la ecología política para explicar las dinámicas entre distintos actores.

Uno de los matices más importantes que nos ofrece un caso como el de Jauja para la discusión más amplia de la producción del espacio viene al momento de identificar los actores que practican el espacio en la zona monumental.

La discusión académica más reconocida sobre los procesos de producción del espacio urbano está construida sobre ciudades metropolitanas con una conectividad global muy patente, las cuales además cuentan con aspectos específicos por sus características demográficas y geográficas (ver Harvey 1989, 1999, 2001, 2008; Castells 1974, 1983; Sassen 2007; Soja 2008; Caldeira 2007; por poner algunos ejemplos representativos).

Por lo general, en estos análisis se identifica que, en los procesos de producción del espacio en tales ciudades, uno de los actores protagonistas son los grupos inmobiliarios. Estos priorizan el valor de cambio del suelo, y son coaliciones delimitables de actores organizados que producen condominios residenciales, centros comerciales, centros industriales o financieros, entre otros (Logan y Molotch, 1987).

Sin embargo, el caso jaujino parece mostrar (a partir de los primeros acercamientos de campo) la producción del espacio en una dimensión mucho menor y de una manera mucho más "descentralizada". En el proceso de transformación del espacio dentro de la zona monumental jaujina, no son exactamente grupos inmobiliarios que solo ven el suelo como una mercancía con valor de cambio, sino que principalmente son residentes (individuos y grupos familiares) quienes producen las nuevas construcciones, y que por esta razón también reconocen el valor de uso y el valor simbólico. No obstante, es innegable que estas construcciones cuentan con patrones estéticos con una regularidad identificable, además de responder a una dinámica económica dirigida a un mayor flujo del capital, generalmente a partir del comercio. 
Otro de los limitantes de la PdE es que este es un concepto que, en tanto parte de un marco totalmente materialista como el marxista, otorga énfasis a los procesos de prácticas espaciales en sus relaciones con las dinámicas económicas (que el autor prefiere denominar "modos de producción") por lo que es muy efectivo para entender estos fenómenos. Sin embargo, desde mi perspectiva, se queda corto al momento de intentar aprehender con profundidad necesaria los procesos simbólicos que acompañan y forman la producción del espacio, y muchas veces termina asumiéndolos como simple consecuencia del proceso estructural (en el sentido de 'infraestructura' de Marx) que acompañan.

Por estas razones, es necesario complementarlo con una propuesta que se enfoque más en el aspecto simbólico, como es la propuesta de los imaginarios urbanos. Esta propuesta tiene la peculiar -e importante- característica de que surge dentro de la academia latinoamericana, principalmente desde autores como Daniel Hiernaux (2007), Alicia Lindón (2007 a; 2007 b) y Armando Silva (2006).

La propuesta de los Imaginarios Urbanos (desde ahora IU) surge como una crítica a la tradición positivista que ha marcado gran parte de los estudios en ciencias sociales. En estos estudios, los procesos subjetivos, de imaginación y simbólicos, son considerados como meros epifenómenos de procesos concretos, y por mucho tiempo se han mantenido marginales por su naturaleza "virtual" que no coincidía con los métodos de aprehensión positivista.

Esta tradición puede notarse en el caso de los estudios urbanos, que como señalan Hiernaux (2007) y Lindón (2007a, 2007b), han sido centralmente estudiados desde perspectivas que privilegian sus aspectos materiales (demografía, arquitectura o urbanismo, economía). Sin embargo, desde el siglo XX y la reivindicación de la experiencia subjetiva a partir de las corrientes fenomenológicas, el interés hacia "procesos imaginales" aumenta, y los imaginarios empiezan a surgir como una categoría presente, aunque con una definición ambigua (Hiernaux 2007, pp.19). Es así que surge la necesidad de encontrar una propuesta teórica que logre definir claramente a ese objeto de estudio, y que traiga consigo una metodología para asirlo. Así, los imaginarios urbanos se gestan como propuesta para entender estos procesos, frente a la inquietud de saber cuáles son los modos simbólicos en los que se vive y se practica la ciudad en Latinoamérica. Por estos motivos, generan un diálogo entre la teoría antropológica, la geografía humanística, el constructivismo e interaccionismo simbólico y el psicoanálisis.

Los imaginarios urbanos, como conceptos, están inherentemente enlazados al espacio, en la medida en que "el espacio es el sensorium general de la función fantástica" (Durand 1969, pp.472 en Hiernaux 2007, pp. 21). Dicho de otro modo, los imaginarios son siempre espaciales, en tanto el espacio se genera como precondición para la existencia de la imagen. 
En esta relación necesaria entre imaginario y espacio, señala Hiernaux:

El espacio urbano tiene un rol espacial en la activación de la imaginación: el urbanita está constantemente afectado por una avalancha de estímulos visuales, que conforman una suerte de puesta bajo tensión permanente, para la percepción humana. A pesar del "hastío", se convierten en un reservorio de imágenes que se construye progresivamente en la mente humana y que adquiere sentido cuando las ordenamos en función de nuestros esquemas previamente construidos y asimilados. (2007:22).

Silva acota en esa misma línea que "En la percepción de la ciudad hay un proceso de selección y reconocimiento que va construyendo ese objeto simbólico llamado ciudad y que en todo símbolo o simbolismo subsiste un componente imaginario". (2006, pp. 97)

Teniendo estas nociones previas de contexto y relación conceptual que los justifica como categoría, los IU son definidos como "la inevitable re-presentación, la facultad de simbolización de la cual emergen continuamente todos los miedos, todas las esperanzas y sus frutos culturales (Durand 1994, pp. 77 en Hiernaux 2007, pp. 20) que funcionan sobre representaciones simbólicas, las cuales hacen posible su traducción.

Silva (2006) los define en tres niveles: como la inscripción física, como posibilidad para la representación colectiva, y como construcción social de la realidad. En estos niveles, los imaginarios se constituyen como una relación indirecta entre la representación simbólica y la realidad experiencial, en la medida en que "los imaginarios son verdades sociales, no científicas, y de ahí su cercanía con la dimensión estética de cada colectividad" (2006, pp. 97). Es decir, que los imaginarios tienen la particularidad de provenir del deseo aún no materializado, y por tanto pueden no tener un correlato material para existir, y de hecho, muchas veces lo preceden y generan.

El corte imaginario que propone Silva nos conduce a un enfrentamiento distinto en su mecánica perceptiva, "estamos ante eventos apenas textualizados y son más bien patrimonio de estructuras implícitas de intercomunicación: la percepción imaginaria corresponde a un nivel profundo pero también concomitante a la del dato empírico". (2006, pp. 98)

E1 IU se manifiesta través de lo simbólico, y tiene la característica de ser un proceso subjetivo a la vez que necesariamente social; es decir, compartido, defendido y enunciado por un grupo de personas. 
Lindón menciona sobre esto que:

Los imaginarios son colectivos -son sociales, son compartidos socialmente-, lo que no debería asumirse como un carácter universal. Pueden estar anclados y ser reconocidos por pequeños círculos sociales o por extensos mundos sociales, pero siempre son un producto de la interacción social entre las personas. Se construyen a partir de discursos, de retóricas y prácticas sociales. Una vez construidos tienen la capacidad de influir y orientar las prácticas y los discursos, sin que ello implique que quedan inmóviles. Por eso producen efectos de realidad. A esto se refiere Hiernaux cuando habla de imágenes guía o imágenes actuantes: son guías para la acción. (2007b, pp. 9)

Esto nos lleva a definir otra de las características de los IU: en la medida en que se constituyen dentro de un grupo como una realidad socialmente construida, incluyen en su definición un sentido normativo: el ser un proyecto a futuro. Ser "imágenes actuantes que buscan llevarse a buen término" en palabras de Hiernaux (2007), o en palabras de Silva:

Como construcción social de la realidad aparece como forma imaginaria de la relación social, pero no está construido, como las imágenes, por la inversión y desvanecimiento del objeto, pues su conformación tiene más que ver con los sueños diurnos que nocturnos y por eso está más orientado hacia el futuro más que hacia el pasado. (2006, pp. 104).

Esta propuesta, además de articular distintas disciplinas y conceptos, propone una nueva metodología para lograr estudiar estos fenómenos.

Primero, Silva (2006) recogió su experiencia de casos en los que él propone ubicar a los actores dentro del universo social a partir de sus capitales (en lenguaje de Bourdieu) para luego entender sus imaginarios sobre la ciudad, cruzando la información recogida con las variables sociales de los actores. Otro de los aportes metodológicos que se debe resaltar es la propuesta de los hologramas espaciales que propone Lindón (2007a) en donde explica que los imaginarios necesariamente necesitan de elementos simbólicos (narrativos, tanto textuales como audiovisuales) para ser traducidos de su carácter "virtual", además que se construyen a partir de las referencias a otros lugares y experiencias.

Como se puede ver, en la medida en que su entrada enfatiza la construcción social y simbólica del espacio, la propuesta de los IU puede incidir en muchos más aspectos que complejicen y complementen el aspecto simbólico que la producción del espacio (PdE) por sí sola no alcanza a tratar con justicia en su concepto de "representaciones".

De hecho, entre los conceptos de "imaginarios" y "representaciones" existen algunas diferencias. 
Una de sus principales diferencias es que mientras las representaciones (en el sentido de la PdE) son -o se plantean- como el correlato simbólico del espacio vivido, y se plantean como una consecuencia del poder o una resistencia a este, los imaginarios no le dan el mismo énfasis a estas relaciones de poder y contrapoder; y aunque sí abordan y atienden a las relaciones de poder que trascienden las simbolizaciones sobre el espacio, lo hacen desde una óptica menos dicotómica de la división entre productores y usuarios que ya señalamos.

Habría que señalar que mientras las representaciones guardan un necesario correlato físico, los imaginarios no tienen un referente o correlato material necesario, y a menudo se forman a través de múltiples procesos selectivos, como el de la memoria (Lindón 2007b, pp. 10). Por esta razón, Silva los denomina como pertenecientes a la "conciencia indirecta" o como "una visión diferente de la real, pero verosímil" (2006, pp. 92). Esta verosimilitud, podríamos decir, radica en el hecho de que pueden convertirse en "reales", a partir de su característica orientadora de las prácticas concretas.

En un sentido general, el concepto de imaginarios es bastante más complejo que el de representaciones, y podría decirse incluso que las contiene.

Hiernaux elabora una sólida definición de tal relación:

La representación en sí no es suficiente ni es el fenómeno que se propone estudiar, ya que el imaginario aporta un complemento de sentido a las representaciones, las transforma simbólicamente para ser tanto guías de análisis como guías de acción (...) La fuerza creativa del imaginario que rebasa la simple representación: el imaginario crea imágenes actuantes, imágenes-guías, imágenes que conducen procesos y no solo representan realidades materiales o subjetivas. (2007: 20-21, énfasis mío).

Sin embargo, esta propuesta teórica alcanza sus límites cuando es forzada a tratar aspectos del tema que, por su entrada y énfasis teórico, no permite tratar con profundidad suficiente. Y aquí me refiero al aspecto de las prácticas, que a pesar de que Hiernaux (2007) propone que es un concepto muy relacionado, me parece riesgoso no incidir con el suficiente detenimiento el tema las dinámicas económicopolíticas para entenderlas, que indudablemente ponen al investigador al tanto de las relaciones estructurales que rodean y dan sentido a estos procesos. Sobre esto, el incidir en el campo de los imaginarios no puede hacernos olvidar que estos tienen una economía-política detrás, en la medida que se generan y reproducen desde grupos con sendos proyectos de reproducción económica y social. En estos, los imaginarios sobre la ciudad son herramientas discursivas no sólo de distinción social (siguiendo a Bourdieu, 1991), sino también eminentemente de disputas en torno a la propiedad del espacio urbano. 


\section{A modo de conclusión}

Desde la descripción del caso se propone que "Jauja monumental", ejecutado entre los años 2008-2011 desde el gobierno regional de Junín (DIRCETUR), y con la participación -en distinto grado- de diferentes actores (entre asociaciones civiles, asociaciones culturales, prensa y residentes), significó la materialización de un imaginario y una propuesta estética y política -desde cierto sector de la sociedad jaujina- sobre la ciudad, su espacio y su desarrollo. Este tiende más a resaltar y proponer una imagen de la ciudad en su aspecto más "tradicional" (en tanto referencia a un pasado oficial de la provincia) y distintivo de otras ciudades de la región; lo cual hace posible pensar en una potencial actividad turística para Jauja. Sin embargo, también se muestra que tal materialización no estuvo -ni está- exenta de disputas materiales y simbólicas en torno al uso y apropiación de dichos espacios por parte de otros sectores de la población con sus propios -y diferentes- proyectos de ciudad.

Como podemos ver, las propuestas de la Producción del Espacio y desde los Imaginarios Urbanos nos permiten abordar con la suficiente profundidad las múltiples aristas del fenómeno del espacio en la zona monumental de Jauja. Si bien, luego de esta revisión de las propuestas, se encuentran bastantes momentos en los que las propuestas se traslapan, en la mayoría de estos se puede ver que las propuestas se complementan de una manera bastante eficiente para lograr atender dichas aristas.

Por un lado, la propuesta de Lefebvre nos permite atender al aspecto económicopolítico que genera una dinámica específica de producción del espacio, vinculada a la relación entre la ciudad y los espacios de circulación de capital más amplios, como el valle del Mantaro o la región Junín. Por otro, la propuesta de Hiernaux, Lindón y Silva, nos permite atender al aspecto simbólico implicado en este proceso. Este tiene que ver con la dinámica de distinción social en Jauja, expresada en los códigos propios de la historia de la ciudad: la clase y la etnicidad, traducidos en el fenómeno de la valoración estética de la arquitectura.

Finalmente, y a modo de reflexión final, creo que, a partir de estos esfuerzos de ir (re)pensando espacios y dinámicas urbanas en escalas menores, se hace necesario un proyecto a largo plazo que implique comenzar a construir sus categorías analíticas propias, tomando en cuenta -de manera referencial- propuestas teóricas como las reseñadas en este artículo. En tal proyecto, creo que un acercamiento desde la antropología es especialmente necesario, en la medida en que su apuesta metodológica desde la etnografía (aspecto que, desde mi opinión personal, es uno de los principales al momento de definir y delimitar a la antropología como disciplina distinta a otras ciencias sociales) permite una contrastación activa de las categorías referenciadas con aquellas que surgen de las prácticas y significaciones de los actores en su devenir cotidiano. 


\section{Bibliografía:}

Baringo Ezquerra, D. (2014). La tesis de la producción del espacio en Henri Lefebvre y sus críticos: un enfoque a tomar en consideración. Quid 16. Revista del Área de Estudios Urbanos, 0(3), 119-135.

Bourdieu, P. (1991). La distinción. Criterios sociales del gusto. Madrid: Taurus.

Caldeira, T. (2007). Ciudad de muros.

Canziani, J., \& Schejtman, A. (2013). Ciudades Intermedias y Desarrollo Territorial. https://doi.org/10.1016/S0141-0229(03)00220-5.L

Castillo Guzmán, G. M. (2015). Transforming andean Space: Local Experiences of Mining Development in Peru. The University of Queensland.

Castells, M. (1983). The City and the Grassroots. Berkeley - Los Angeles: University of California Press.

\section{(1974). La Cuestión Urbana. Madrid: Siglo XXI.}

Correa Solís, O. (2018). Entre la teja y la mayólica: representaciones del espacio sobre la ciudad de Jauja a partir del proyecto "Jauja Monumental". Lima: Repositorio Institucional PUCP.

Creswell, T. (2008). Place: A Short Introduction. Coverty, United Kingdom: Blackwell publishing.

Harvey, D. (2008). París, capital de la modernidad (Vol. 53). Ediciones Akal. (2001). Spaces of capital: Towards a critical geography. Routledge.

(1999). The limits to capital (New ed.). London and New York: Verso. (1989). The condition of postmodernity (Vol. 14). Oxford: Blackwell.

Hiernaux, D. (2007). Los imaginarios urbanos: De la teoría y los aterrizajes en los estudios urbanos. Eure, 33(99), 17-30. https://doi.org/10.4067/S025071612007000200003

Lefebvre, H. (2013). La producción del espacio. Madrid: Capitán Swing, 2013. Recuperado a partir de http://ezproxybib.pucp.edu.pe:2048/login?url=http:// search.ebscohost.com/login.aspx ?direct $=$ true $\& d b=$ cat02225a $\& A N=$ pucp. a550394\&lang=es\&site $=$ eds-live\&scope $=$ site

Lindón, A. (2007). La ciudad y la vida urbana a través de los imaginarios urbanos. Revista Eure, XXXIII, 7-16. https://doi.org/10.4067/S0250-71612007000200002 
(2007). Los imaginarios urbanos y el constructivismo geográfico: Los hologramas espaciales. Eure, 33(99), 31-46. https://doi.org/10.4067/S025071612007000200004

Logan, John \& Harvey Molotch. (1987). Urban Fortunes: The Political Economy of Place. Berkeley - Los Angeles: University of California Press.

Metzger, P., Rebotier, J., Robert, J., Urquieta, P., \& Centeno, P. V. (2016). La cuestión urbana en la región andina.

Oslender, U. (2002). Espacio, lugar y movimientos sociales: Hacia una "espacialidad de resistencia". Scripta Nova: Revista electrónica de geografía y ciencias sociales, VI(115).

Rivera Martínez, E. (1999). Imagen de Jauja. Huancayo: Universidad Nacional del Centro del Perú.

Rivera Martínez, E., \& Vegas de Cáceres, I. (2012). Historia y leyenda de la Tierra de Jauja : antología. Lima : Fundación Manuel J. Bustamante De la Fuente.

Salcedo, Andrés; Zeiderman, A. (2008). Antropología y Ciudad: Hacia un análisis crítico e histórico. Antipoda, 63-97.

Sánchez Aguilar, A. (2015). Migraciones internas en el Perú. Lima: OIM.

Sassen, S. (2007). "Capítulo 3: Ciudades globales: la recuperación del lugar y las prácticas sociales”. En: Una sociología de la globalización. Buenos Aires: Katz ed.

Shields, R. (1988). Henri Lefebvre : La Production de L 'espace. Universidad de Sussex, 2(April 1988).

Silva, A. (2006). Imaginarios urbanos. Recuperado a partir de https:// imaginariosyrepresentaciones.files.wordpress.com/2015/05/silva-armandoimaginarios-urbanos.pdf

Soja, E. W. (2008). Postmetrópolis: estudios críticos sobre las ciudades y las regiones. Traficantes de sueños.

Tuan, Y.-F. (1979). Space and place : the perspective of experience. 